\title{
Insight
}

\section{Bridges and Barriers to Developing and Conducting Interdisciplinary Graduate-Student Team Research}

\author{
Wayde Cameron Morse $^{1,2}$, Max Nielsen-Pincus ${ }^{1}$, Jo Ellen Force ${ }^{1}$, and J. D. Wulfhorst ${ }^{1}$
}

\begin{abstract}
Understanding complex socio-environmental problems requires specialists from multiple disciplines to integrate research efforts. Programs such as the National Science Foundation's Integrative Graduate Education and Research Traineeship facilitate integrated research efforts and change the way academic institutions train future leaders and scientists. The University of Idaho and the Tropical Agricultural Research and Higher Education Center in Costa Rica collaborate on a joint research program focusing on biodiversity conservation and sustainable production in fragmented landscapes. We first present a spectrum of integration ranging from disciplinary to transdisciplinary across seven aspects of the research process. We then describe our experiences and lessons learned conducting interdisciplinary graduate student team research. Using our program as a case study, we examine the individual, disciplinary, and programmatic bridges and barriers to conducting interdisciplinary research that emerged during our student team research projects. We conclude with a set of recommendations for exploiting the bridges and overcoming the barriers to conducting interdisciplinary research, especially as part of graduate education programs.
\end{abstract}

Key Words: integration; interdisciplinary; team research; sustainability; biodiversity; graduate education; Integrative Graduate Education and Research Traineeship; University of Idaho; Tropical Agricultural Research and Higher Education Center (CATIE)

\section{INTRODUCTION}

Many academic and scientific institutions now recognize the need for an interdisciplinary education to prepare future managers, scientists, and leaders to solve complex socio-environmental problems (Ewel 2001, National Academy of Sciences et al. 2005). An increasing number of universities have added programs that support cross-disciplinary perspectives (Zarin et al. 2003, Rhoten 2004). However, many academic institutions still address critical topic areas such as biodiversity conservation and sustainable development through discipline-bound approaches. Invocation of the term "interdisciplinary" is rarely accompanied by a definition of the entire research process.

Barriers to expanding beyond traditional disciplinary research structures include a lack of funding for interdisciplinary research, a lack of historical interdepartmental or cross-disciplinary cooperation, extended time requirements, differences in methodologies and disciplinary norms, turfism, and egos (Brewer 1999, Golde and Gallagher 1999, Younglove-Webb et al. 1999, Lele and Norgaard 2005, Eigenbrode et al. 2007). These factors can be especially burdensome in a university research setting in which graduate students are required to meet traditional departmental graduation requirements. These institutional barriers generate trained incapacities (Rosa and Machlis 2002) in professionals who are not prepared to collaborate across disciplines in an integrated manner and lack the capacity to address increasingly complex scientific dilemmas (Sillitoe 2004). Thus, although disciplinary specialization has led to great advancements in science and is critical, it alone is often not sufficient to create either knowledge or researchers capable of solving today's complex problems (Klein 2004).

The National Science Foundation (NSF) designed the Integrative Graduate Education and Research Traineeship (IGERT) program to overcome these 
institutional barriers. The NSF goal for the IGERT program is [to produce graduate students] "with the interdisciplinary backgrounds, deep knowledge in chosen disciplines, and technical, professional, and personal skills to become in their own careers the leaders and creative agents for change. The program is intended to catalyze a cultural change in graduate education for students, faculty, and institutions, by establishing innovative new models for graduate education ... for collaborative research that transcends traditional disciplinary boundaries" (National Science Foundation 2006). With financial support for the IGERT program, the NSF is attempting to foster the institutional capacity for integrative research and education programs within U.S. universities.

Our objective in this paper is to share several critical insights we have learned about interdisciplinary research and education at the midpoint in an IGERT program jointly delivered at the University of Idaho and the Tropical Agricultural Research and Higher Education Center in Costa Rica. This program will hereafter be referred to as "our joint interdisciplinary program." We present a typology built from the literature referenced in the following section that defines interdisciplinary research in relation to other types of integration. We explain the individual, disciplinary, and programmatic bridges and barriers to conducting interdisciplinary graduate-student research that were identified by program participants during our project evaluation workshop. Finally, we offer a set of recommendations for exploiting bridges and overcoming barriers intended to further awareness and understanding of the challenges of conducting interdisciplinary graduate-student research.

\section{SPECTRUM OF INTEGRATION}

Integrated research commonly refers to a process of coordinated, collaborative, or combined inquiry into a common problem with sharing, creation, and synthesis of knowledge among disciplines and researchers (Klein 1996, Clark et al. 1999). Previous conceptualizations offer a research integration typology that includes the core spectrum of disciplinary, multidisciplinary, interdisciplinary, and transdisciplinary research (Jantsch 1970, Rosenfield 1992, Klein 1996, Pickett et al. 1999, Somerville 2000, Stokolos 2003, Jakobsen et al. 2004). Building on this literature, Table 1 differentiates these four types of integration across seven research concepts that help to illustrate important differences across the spectrum: (1) level of interaction among team members; (2) problem definition; (3) epistemology; (4) design, research, questions, methods, and theory; (5) knowledge generation; (6) academic programs; and (7) research products.

Within this spectrum, interdisciplinary research is distinct in its level of coordination among researchers and across research concepts. Our joint interdisciplinary program has the goal of achieving the second level of integration: interdisciplinary research. The project seeks to create graduatestudent research teams with the following characteristics: (1) students and their major professors interact with other team members throughout the life of the project; (2) the teams develop a common research problem and mutually define a conceptual framework consistent with the multiple epistemologies potentially represented within the team; (3) teams coordinate research questions, methods, and scales into a framework that synchronizes the structure of the research process; and (4) research outcomes are expected to include data impacting the knowledge structures of each of the represented disciplines, resulting in a synthetic, rather than disciplinary, product. In the NSF IGERT program, graduate research work may be conducted independently within the students' home disciplines; however, the funding also facilitates integrated team projects.

Table 1 serves as a heuristic tool to summarize the relative differences across the spectrum of integrated research in general. The spectrum does not imply that different points on the continuum constitute right or wrong approaches. Instead, the critical point is that the different levels of integration provide the ability to address fundamentally different problems as a result of coordinating or combining research concepts, methods, and results. Table 1 establishes a contextual point of departure for understanding the challenges and strategies to overcome when conducting different levels of integrated research, and in particular those addressed by our joint interdisciplinary program.

\section{CASE STUDY: GRADUATE-STUDENT TEAM RESEARCH}

In 2001, the National Science Foundation awarded a collaborative University of Idaho (UI)-Tropical 
Table 1. Spectrum of disciplinary integration in scientific research based on the literature referenced.

\begin{tabular}{|c|c|c|c|c|}
\hline & Disciplinary & Multidisciplinary & Interdisciplinary & Transdisciplinary \\
\hline $\begin{array}{l}\text { Integration } \\
\text { vocabulary }\end{array}$ & $\begin{array}{l}\text { Independent: } \\
\text { self-reliant and } \\
\text { autonomous }\end{array}$ & $\begin{array}{l}\text { Collaborative: } \\
\text { work together, join forces, } \\
\text { team up, and cooperate }\end{array}$ & $\begin{array}{l}\text { Coordinated: } \\
\text { organized, synchronized, } \\
\text { harmonized, and mutual }\end{array}$ & $\begin{array}{l}\text { Combined: } \\
\text { joint, shared, collective, and } \\
\text { transcending }\end{array}$ \\
\hline $\begin{array}{l}\text { Level of } \\
\text { interaction }\end{array}$ & $\begin{array}{l}\text { Researchers conduct } \\
\text { independent research. }\end{array}$ & $\begin{array}{l}\text { Team members } \\
\text { cooperatively conduct } \\
\text { research in parallel. }\end{array}$ & $\begin{array}{l}\text { Team members } \\
\text { coordinate frequently and } \\
\text { consistently throughout } \\
\text { the project. }\end{array}$ & $\begin{array}{l}\text { Team members act, plan, and } \\
\text { combine research as a } \\
\text { collective. }\end{array}$ \\
\hline $\begin{array}{l}\text { Problem def- } \\
\text { inition }\end{array}$ & $\begin{array}{l}\text { Guided by } \\
\text { disciplinary paradigm }\end{array}$ & $\begin{array}{l}\text { Usually guided by one } \\
\text { disciplinary paradigm and } \\
\text { often framed by lead } \\
\text { discipline }\end{array}$ & $\begin{array}{l}\text { Mutually developed by } \\
\text { researchers from multiple } \\
\text { disciplines }\end{array}$ & $\begin{array}{l}\text { Transcends disciplinary } \\
\text { boundaries; context-specific } \\
\text { with multiple stakeholder } \\
\text { perspectives }\end{array}$ \\
\hline Epistemology & $\begin{array}{l}\text { Researchers rely on } \\
\text { disciplinary episte- } \\
\text { mology. }\end{array}$ & $\begin{array}{l}\text { Team members rely on } \\
\text { disciplinary epistemology, } \\
\text { but of differing paradigms. }\end{array}$ & $\begin{array}{l}\text { Team members may rely } \\
\text { on disciplinary } \\
\text { epistemology, but must } \\
\text { accept the validity of } \\
\text { different paradigms. }\end{array}$ & $\begin{array}{l}\text { Team members rely on a } \\
\text { transcendent or common } \\
\text { epistemology that reflects the } \\
\text { nature of the problem } \\
\text { definition. }\end{array}$ \\
\hline $\begin{array}{l}\text { Design, rese- } \\
\text { arch questions, } \\
\text { methods, and } \\
\text { theory }\end{array}$ & $\begin{array}{l}\text { Researchers use } \\
\text { traditional disciplinary } \\
\text { approaches. }\end{array}$ & $\begin{array}{l}\text { Team members use } \\
\text { traditional disciplinary } \\
\text { approaches; research } \\
\text { questions and scales are } \\
\text { framed by the discipline } \\
\text { that defined the problem. }\end{array}$ & $\begin{array}{l}\text { Team members } \\
\text { coordinate research } \\
\text { design, questions, } \\
\text { methods, and theory; } \\
\text { temporal and spatial } \\
\text { scales and conceptual } \\
\text { frameworks are } \\
\text { synchronized. }\end{array}$ & $\begin{array}{l}\text { Team members develop new } \\
\text { conceptual framework that } \\
\text { transcends disciplinary } \\
\text { boundaries; research design, } \\
\text { questions, methods, and scales } \\
\text { are collectively developed. }\end{array}$ \\
\hline $\begin{array}{l}\text { Knowledge } \\
\text { generation }\end{array}$ & $\begin{array}{l}\text { Knowledge created } \\
\text { within discipline, } \\
\text { and conclusions } \\
\text { may generate new } \\
\text { disciplinary research } \\
\text { questions }\end{array}$ & $\begin{array}{l}\text { Knowledge created within } \\
\text { disciplines, but conclusions } \\
\text { may generate research } \\
\text { questions that are applicable } \\
\text { to other disciplines }\end{array}$ & $\begin{array}{l}\text { Knowledge created that } \\
\text { may impact knowledge } \\
\text { structures in all } \\
\text { disciplines; conclusions } \\
\text { generate new types of } \\
\text { interdisciplinary research } \\
\text { questions }\end{array}$ & $\begin{array}{l}\text { Knowledge restructured } \\
\text { through the creation of new } \\
\text { shared knowledge; } \\
\text { conclusions drive new } \\
\text { theoretical frameworks and } \\
\text { areas of research }\end{array}$ \\
\hline Products & $\begin{array}{l}\text { Disciplinary; for } \\
\text { disciplinary journals }\end{array}$ & $\begin{array}{l}\text { Disciplinary or summary of } \\
\text { combined disciplinary } \\
\text { findings; for disciplinary } \\
\text { journals }\end{array}$ & $\begin{array}{l}\text { Joint synthesis } \\
\text { manuscripts; for } \\
\text { interdisciplinary journals }\end{array}$ & $\begin{array}{l}\text { Joint synthesis manuscripts } \\
\text { that transcend disciplinary } \\
\text { orientations; for } \\
\text { interdisciplinary journals }\end{array}$ \\
\hline
\end{tabular}

Agricultural Research and Higher Education Center (known as CATIE, the acronym of its Spanish name, the Centro Agronómico Tropical de Investigación y Enseñanza) faculty team an Integrative Graduate Education and Research Traineeship (IGERT) grant for an international, interdisciplinary graduate research and education program with the theme of "biodiversity conservation and sustainable production in anthropogenically fragmented landscapes" (Bosque-Pérez et al. 2001). The project engages students and faculty in interdisciplinary thinking and increases their ability to work effectively in interdisciplinary teams by jointly defining research questions and developing research designs that integrate theoretical knowledge with practical problem solving. 
Eighteen doctoral students, in four cohorts recruited over two years, are participating in the project. Student enrollment spans departments in the UI College of Natural Resources, College of Agricultural and Life Sciences, and Environmental Science Program as well as CATIE through an institutionalized joint doctoral program. The IGERT project provides students with international experience, multi-institutional perspectives, and diverse resources for coursework and mentoring not conventional to disciplinary doctoral programs. Research teams operate in agricultural and forested landscapes in Costa Rica and Idaho, USA.

As a central and innovative element of the program's structure, students conduct research on an interdisciplinary team and include in their dissertation at least one co-authored interdisciplinary chapter resulting from their team's collaborative work. The students represent a wide range of disciplines including botany, economics, entomology, forest ecology, wildlife and plant genetics, hydrology, remote sensing, rural sociology, soil sciences, and wildlife biology. Five teams of students and faculty mentors have formed; three of these are conducting research in Costa Rica, and two in northern Idaho. All five teams contain members from at least three disciplines.

The structure of the academic program (Table 2) was designed by the UI-CATIE project faculty to help institutionalize interdisciplinary research within the two institutions (University of IdahoCATIE 2006). These programmatic components enhance the rigor of the disciplinary training students receive through their home departments with interdisciplinary learning. The program design supports the NSF IGERT program goals of transcending disciplinary boundaries and facilitating research at the interdisciplinary level.

\section{METHODS}

There are a few studies that formally examine the issues that facilitate or encumber a functioning interdisciplinary research team in academia (Golde and Gallagher 1999, Younglove-Webb et al. 1999, Bruce 2004, Jakobsen et al. 2004, Eigenbrode et al. 2007). However, analyses of interdisciplinary teams of Ph.D. students conducting integrated research do not yet exist. To document and share our experience with interdisciplinary integration, we conducted a series of workshop exercises during an annual project meeting in Moscow, Idaho, held on May 17-21, 2004. All the students, most of the faculty, and three external advisory panel members participated in the workshops. We facilitated group dialogue, separate faculty and student sessions, and individual program evaluations to document the perceptions of the integration processes underway. We categorized and coded the data from each session into three emergent themes to facilitate indepth discussion on each specific theme. At the end of the meeting, we presented a synthesis of the results to validate the findings with the participants. The process generated a framework for continued dialogue on effective means for conducting interdisciplinary research within our program consistent with participatory social science methodologies that engage respondents for review of data and results (Creswell 2003). Identifying and understanding the issues that help and hinder graduate-student team research integration offers the opportunity to use the bridges more effectively and overcome the barriers.

\section{RESULTS}

The three themes of bridges and barriers to interdisciplinary graduate-student research that emerged from our workshop were classified as individual, disciplinary, or programmatic and are presented in Tables 3, 4, and 5, respectively. Each theme is further coded into categories and issues that were found to directly affect interdisciplinary success within our program. We found that each issue is positioned on a spectrum and can become a bridge or a barrier depending on team context. For example, the issue of "taking risks" to work with the unfamiliar can be a bridge to integration if the individual is willing to try something new and push disciplinary boundaries, or a barrier if the student prefers only to conduct traditional disciplinary research. The extent to which the individual is willing to take risks will determine whether this issue is a bridge or a barrier toward integration for that particular person.

\section{Individual bridges and barriers}

Our experience suggests that bridges and barriers to conducting integrated research begin at the individual or personal level. We find three 
Table 2. Academic structure of the University of Idaho (UI)-Tropical Agricultural Research and Higher Education Center (CATIE) Integrative Graduate Education and Research Traineeship program (University of Idaho-CATIE 2001).

\begin{tabular}{ll}
\hline \hline Programmatic component & Description \\
\hline Mentorship & $\begin{array}{l}\text { Co-advisors (UI and CATIE) required for students conducting research in Costa } \\
\text { Rica; committee member on all student committees from both the UI College of } \\
\text { Natural Resources and College of Agricultural and Life Sciences }\end{array}$ \\
Team research project & $\begin{array}{l}\text { Students training in different disciplinary fields work together to jointly define } \\
\text { research problems and conduct interdisciplinary research. }\end{array}$ \\
Dissertation chapters & $\begin{array}{l}\text { Students must include at least one co-authored interdisciplinary chapter in their } \\
\text { dissertation in addition to departmental dissertation requirements. }\end{array}$ \\
Interdisciplinary courses & $\begin{array}{l}\text { Interdisciplinary Research in Biodiversity Conservation and Sustainability, a three- } \\
\text { credit course used to develop team proposals; } \\
\text { Current Issues in Biodiversity Conservation and Sustainability, a semi-annual } \\
\text { seminar used to explore the literature across a variety of disciplines and promote } \\
\text { interdisciplinary dialogue }\end{array}$
\end{tabular}

Cross-disciplinary coursework

Preliminary exam

Internship

Annual program meeting
Two required courses in each of four core areas: (1) social science and ethics, (2) economics, (3) biophysical sciences, and (4) agriculture or forestry

Interdisciplinary component of each student's qualifying exam

3- to 6-month research internship required for each student to develop breadth of international and/or interdisciplinary experience

Field visits to student research sites, student/faculty symposia focusing on team research, and interdisciplinary training workshops categories of personal characteristics that foster bridges and barriers in interdisciplinary research: vision, dedication, and problem solving (Table 3). An individual's vision factors into issues of risk taking, flexibility, a common vision, creativity, and cross-disciplinary thinking. As one workshop participant pointed out, "Not everybody is willing to go out on a limb, but somebody has to in order to bridge the gaps between our disciplines." Similarly, the willingness of researchers to craft their disciplinary focus around a complex common problem signifies a level of flexibility necessary to mutual problem definition. Creativity and the ability to think across disciplines also constitute vision characteristics that can facilitate team-based problem definition, research design, and analyses.

Dedication to the interdisciplinary process is a second important category of individual issues.
Dedication includes a researcher's commitment, professionalism/accountability, and patience.

Interdisciplinary research requires team members to be committed to providing data and results to other team members to advance the objectives of the group in addition to those of the individual. However, as stated by one workshop participant, "There is a dichotomy between the disciplinary and the interdisciplinary demands; we're trying to break the barriers of our research traditions while at the same time maintain them." This pull between one's disciplinary and interdisciplinary activities may become a tension in many routine research activities. Often a team member's completion of a specific task depends upon another team member completing his or her tasks. Thus, patience with the progress of the interdisciplinary project becomes a valuable asset toward the accomplishment of interdisciplinary objectives. 
Table 3. Individual bridges and barriers to integrated interdisciplinary research.

\begin{tabular}{lcl}
\hline \hline \multicolumn{1}{c}{ Barriers } & Codes & Bridges \\
\hline & Vision & \\
$\begin{array}{l}\text { Preference for "traditional" disciplinary } \\
\text { work }\end{array}$ & Risk taking & $\begin{array}{l}\text { Willingness to try something new and push } \\
\text { disciplinary boundaries }\end{array}$ \\
$\begin{array}{l}\text { Rigid adherence to individual disciplinary } \\
\text { project }\end{array}$ & Flexibility & $\begin{array}{l}\text { Willingness to adjust disciplinary focus to make } \\
\text { team project work }\end{array}$ \\
$\begin{array}{l}\text { Focused on disciplinary mechanics } \\
\text { Common vision }\end{array}$ & $\begin{array}{l}\text { Focus on resolving research problem from } \\
\text { holistic perspective }\end{array}$ \\
$\begin{array}{l}\text { Lack of creativity; focus on disciplinary } \\
\text { "depth" as an indicator of rigor }\end{array}$ & Creativity & $\begin{array}{l}\text { Creatively designing a project that is integrated } \\
\text { and rigorously meets both "depth" and "breadth" } \\
\text { criteria }\end{array}$
\end{tabular}

Not willing/able to think in terms of other disciplines

Cross-disciplinary thinking Ability to think holistically, make connections

Dedication

Team projects as secondary, separate project

Not meeting self-imposed deadlines

Focus on individual timeline, not adaptable

ignored" attitude

Infrequent, distant, disorganized, simplistic updates

Little experience working in teams and across disciplines
Commitment

Professionalism/ account- Meeting commitments and deadlines ability

Patience

Problem solving

Conflict resolution

Communication strategy Adherence to team-created timelines, but adaptable

Dedicated to integrated project as an equal or greater priority to disciplinary work

Active communication to resolve/overcome barriers

Frequent, personal, dependable, in-depth, professional

Experience Lots of experience working in teams and across disciplines
Problem-solving orientation constitutes a third category of individual bridges and barriers to the interdisciplinary process. Problem solving includes issues of conflict management, communication strategies, and experience. Similar to group dynamics elsewhere, proactive communication when problems arise can avert the conflicts and challenges associated with interdisciplinary design.
During the workshop, many individuals reflected on the importance of team members with prior integration or team experience. "Some students are farther along in their work than others or have a strong team background, both of which can benefit the rest," remarked one participant. Another team member noted, "I joined an existing team with an existing framework, which made identifying a niche 
Table 4. Disciplinary bridges and barriers to integrated interdisciplinary research.

\begin{tabular}{ccc}
\hline \hline Barriers & Codes & Bridges \\
\hline
\end{tabular}

Idiosyncrasies

Unique language/jargon, more technical background necessary

Lack of understanding of different paradigms or single-paradigm bias

Poor match between extent of variables or processes

Poor match between "speed" of variables or processes

Few common units, standards, measurements

Disjointed data gathering seasons

No current models

Lack of necessary disciplines

Disciplines on team have incommensurabilities that make answering management/conservation questions difficult

Diverse or multiple systems, policies, programs or process

No unifying theme

Different audiences

\section{Language}

Paradigm

Scales and units

Spatial scale

Temporal scale

Metrics

Timing

Models and frameworks

Examples of interdisciplinary work

Team make-up

Focus theme

Problem centered/applied results

Topical/systematic focus

Unifying theme/focus
Common or easy-to-understand language/jargon, less technical background necessary

Understanding of different paradigms or accepting multiple-paradigms
Good match between extent of variables or processes

Good match between "speed" of variables or processes

Common units, standards, measurements

Coordinated data gathering seasons
Existing examples of models that include relevant disciplines and data; predictive or descriptive

Good fit to context of local problem
Disciplines on team can combine to answer management/conservation questions

Single system, crop, policy, program, or process

Unifying theme, such as spatial (GIS based) or social (management/ conservation), that links research

Common audiences 
Table 5. Programmatic bridges and barriers to integrated interdisciplinary research.

\begin{tabular}{ccc}
\hline \hline Barriers & Codes & Bridges \\
\hline
\end{tabular}

Framework

No focus to guide teams or research

Interdisciplinary projects as "add-ons", primary focus on disciplinary project not associated with team project

Traditional approaches to framing research

Less integration experience or support

Integrated portions of proposal not supported by disciplinary advisors

Programmatic/bureaucratic details for two institutions

Language, logistics, access are more difficult.

Not experts in all aspects of own discipline or interdisciplinary models/ frameworks

Insufficient funding

Disciplinary work may take less time

Exams focus narrowly on discipline
Depth versus breadth

Mentoring

Broad and flexible research topic

Disciplinary or interdisciplinary focus

Advisor experience/commitment

Proposal writing

CATIE partnership

International research

Training and resources

Technical training

Funding

Time

Preliminary Exams
Flexibility to choose research

Creative synthesis to make individual disciplinary research part of integrated project

Innovation and freedom to create projects that focus on interactions and systems
More integrated experience and support

Integrated portions of proposal supported by disciplinary advisors

Local expertise and contacts

Language, logistics, access facilitated by local contacts

Strong disciplinary background and training in interdisciplinary models/ frameworks

Sufficient funding

Integrated work may take longer

Exams are comprehensive of interdisciplinary topic possible." In some teams, a de facto leader emerged who managed the conflicts that arose.

\section{Disciplinary bridges and barriers}

We identified four categories of disciplinary issues that foster bridges and barriers in interdisciplinary research: idiosyncrasies, scales and units, models and frameworks, and focal themes (Table 4). Disciplinary idiosyncrasies include language and paradigms. One team member reflected that, "I sometimes used words that had no meaning to my team members, or we were using the same words with completely different definitions. It was a real struggle until we realized the need for a common language between us." Researchers who learn the language and the scientific paradigms of other team 
members can be assets to interdisciplinary knowledge generation. Additionally, a mutual understanding of team paradigms may develop into critical epistemological foundations for the successful interdisciplinary project.

A particular challenge for interdisciplinary projects such as ours, which is focused on social and biophysical ecosystems in a specific geographic location, is integration across various scales using different measurement units. Our teams include biophysical scientists ranging from conservation geneticists working at the molecular level to landscape ecologists working across hundreds of square kilometers, all of whom must integrate with social scientists working at various scales from the household to region. One workshop participant compared the challenge of interdisciplinary team integration to building a bicycle: "Building the wheel is difficult enough when one person builds the wheel; now try to have three to five people working on the wheel with different tools and different ideas about what kind of bike it will go on." Identifying spatial and temporal scales and variables that can be coordinated, measured, and integrated across scales and disciplines has challenged all the students and faculty in our program, and little guidance is available in the disciplinary literatures. Tools such as GIS and statistical modeling techniques that can integrate data at different scales have emerged as bridges to the successful generation of interdisciplinary knowledge. There are also temporal challenges to coordinating interdisciplinary research design, because data collection in some disciplines requires several field seasons, whereas others may require one intensive data-collection period.

Models and frameworks that have been developed through past interdisciplinary research greatly facilitated integration on our teams. Disciplinary bridges and barriers highlight the challenge associated with having the "right" disciplines involved to address a particular interdisciplinary research question. In our joint interdisciplinary program, teams formed around geographic areas of interest, resulting in some teams identifying an interdisciplinary problem that "fit" the disciplinary makeup of the team, whereas other teams lacked the full range of disciplines needed to address the problems identified in their geographic areas. As a result, some areas of inquiry in the interdisciplinary research problem remained unfulfilled. Our joint interdisciplinary program has mitigated the problem of "missing disciplines" through internships and short-term fellowships for other masters and doctoral students to fill the gaps in a specific interdisciplinary team.

Finally, we found that a focal theme that highlights issues related to the problem application, the topical system, the unifying analysis, and/or the research audience can help facilitate interdisciplinary interaction, knowledge generation, and the production of meaningful results. Focal themes served as an important communication device for our teams to frame complex interdisciplinary problems. For instance, research questions addressing the impacts of land-use change or payments for environmental services were found to help frame our integrated activities.

\section{Programmatic bridges and barriers}

Last, we identified three categories of bridges and barriers at the programmatic level: framework, mentoring, and training and resources (Table 5). The broad ranging University of Idaho-Tropical Agricultural Research and Higher Education Center IGERT framework of biodiversity conservation and sustainable production in fragmented landscapes allowed teams to have flexibility in their research design. Although this flexibility was a bridge for the creativity of some teams in the problem definition and research design phase, it also became a barrier for others because of the lack of guidance in the form of specific questions and research topics. Second, although the jointly authored chapters required by our project in the dissertations were an innovative part of our program framework, in some cases they created trade-offs between disciplinary and interdisciplinary responsibilities. We found evidence of bridges when disciplinary and interdisciplinary projects complemented one another. A third issue associated with the programmatic framework highlights the concern for balancing depth and breadth. Interdisciplinary researchers must be able to frame their work in terms of both depth or mechanisms and breadth or systems to identify the internal and emergent properties of the research setting. The tension between depth and breadth presented a barrier to some team members, who alluded to the practical constraints of operating within a traditional degree-granting department, and a bridge to others, who noted that it helped them better understand the larger systems to which their work may relate. One workshop participant, 
commenting on student backgrounds, noted that those teams with "students who brought disciplinary depth to the team allowed integration to be a process for learning that facilitated the interdisciplinary product." A focus on in-depth understanding of interactions within complex systems and across disciplines may be an important way to reframe the depth vs. breadth discussion.

Workshop participants suggested that the prior experience of faculty mentors with interdisciplinary research affected their ability to assist students to negotiate the challenges of interdisciplinary graduate education. Although our data did not identify specific mentor qualities, we believe that the same qualities and traits identified as facilitating interdisciplinary research for students similarly apply to mentors. Program requirements for international experience and cross-disciplinary mentorship across the involved colleges and institutions created logistical barriers, but also facilitated new collaborative research opportunities for both faculty and students.

We found four training and resource issues that caused bridges and barriers, including technical training, funding, time, and doctoral preliminary exams. Technical training in integrated frameworks, joint proposal writing, and learning appropriate analytic tools for the interdisciplinary project can significantly affect the timely completion of the research tasks outlined in the interdisciplinary research framework. Some participants considered the time necessary to complete both the disciplinary and interdisciplinary requirements of our joint interdisciplinary program as a fundamental challenge in their program. Related to time, funding is also a critical resource for all graduate students. Integrated research in graduate education may present additional financial challenges. Our joint interdisciplinary program provided competitive multiyear graduate stipends for three years, funding for professional travel, and a limited research operations budget. Garnering the necessary financial support for interdisciplinary operations presented further challenges in terms of coordination and proposal writing. However, we found that writing, and in some cases securing, team-based proposals for interdisciplinary project funding greatly facilitated the establishment of team objectives and accountability to the project throughout the stages of research.

\section{RECOMMENDATIONS}

Based on the experiences of our joint interdisciplinary program and related literature on integrated research, we offer nine recommendations to exploit the bridges and overcome the barriers to interdisciplinary integration. Although these recommendations may take a number of forms depending on the particular research project, our recommendations and examples should provide critical discussion topics prior to embarking on an interdisciplinary project. Our review of the literature suggests that many of our recommendations for an interdisciplinary graduate research program also apply to interdisciplinary team research efforts in general.

\section{Establish an accountability strategy}

Individual accountability is a necessary feature of integrated work and the means by which researchers depend on one another. The team-developed proposal can be a living social contract between team members. It helps team members articulate their own expectations and individual characteristics and better understand those of other team members. This is especially important in the graduate-student research team environment (see also Graybill et al. 2006). Others (see, e.g., Clark et al. 1999, Younglove-Webb et al. 1999) have also found that, in the face of shifting individual priorities and deadlines, an accountability strategy clarifying interdisciplinary team timelines, requirements, and responsibilities is essential. For example, the accountability strategy may include timelines and due dates for portions of the project, interim reports, and guidelines for project adjustment and conflict resolution.

\section{Develop formal and informal communication strategies}

Success with integrated research requires the development of a formal communication strategy specifying how, when, and what researchers should communicate as well as plans to complete analyses and written products. At greater degrees of integration across the spectrum, team members must engage in recurrent interaction as an essential part of mutual learning. Team meetings should include activity updates when appropriate, but meetings should also serve as opportunities for 
ongoing dialogue about the research problem, design, methods, analyses, and conclusions as well as disciplinary differences in paradigms, scales, and frameworks. Communication should not simply remain formal. Regular informal interaction can facilitate many of the bonds and relationships necessary for effective teamwork at the individual and programmatic levels. However, the academic environment and its wide variety of professorgraduate student relationships may present unique communication challenges

\section{Select team members thoughtfully and strategically}

Bridges for integrated research can form with thoughtful and strategic selection of the disciplines needed and the individual participants able to fill those positions. Interdisciplinary team members must cooperate, share leadership, and demonstrate responsibility (Naiman 1999). Researchers who operate successfully in creative, flexible, and riskadaptive settings may thrive when conducting interdisciplinary work. Selecting team members with vision, dedication, and problem-solving characteristics can set the team on a trajectory toward success from the start. Janssen and Goldsworthy (1996:268) summarize these qualities well: "Synthetic research will require team members who are good at brainstorming, who are able to overcome their own disciplinary limitations in creative interaction, and who are prepared to make their own research plans fully contingent on the plans of the team."

\section{Address temporal and spatial scale issues}

Clearly defining a problem becomes essential for each team member to conduct research within the range of temporal and spatial scales inherent to the problem definition (Pickett et al. 1999). Scale decisions determine the extent and hierarchy of the system under investigation. Outlining different disciplinary scales and scale theories (e.g., Gunderson and Holling 2002) facilitates understanding of the interdisciplinary challenges of the research project, exposes researchers to the paradigms of their colleagues from other disciplines, and fosters problem-solving strategies. Interdisciplinary teams challenge themselves by choosing scales that may not resonate with traditional and cultural norms within the individual disciplines involved (e.g.,
Benda et al. 2002). However, our cumulative experience reveals that creativity in methods and research design throughout the research project can overcome many of the temporal and spatial scale issues in interdisciplinary natural resource and environmental science research.

\section{Recognize and respect timing issues}

Different disciplines require different amounts of time to complete research and, in the natural resource and environmental sciences, datagathering seasons, breeding cycles, social activities, and other temporal factors may be crucial for successful projects. In the early stages of team formation, it is critical to develop a team timeline and establish a research framework that outlines the responsibilities and deadlines of each team member. This framework and associated timeline should reflect the time necessary to develop a common language, activities that build trust and relationships, and a mutual understanding of the problem and the conceptual model. The research timeline should focus on the sequencing of and responsibilities for research activities so that data synthesis, analysis, and the writing of results may occur in a coordinated and timely manner. These factors should be included in the accountability strategy. It should also be recognized that, as researchers move from doing disciplinary to transdisciplinary research, the research process may take longer.

\section{Define focal themes and research questions jointly and clearly}

Integrated research teams should create a focal theme that ties each individual component of the research to the common team vision through a description of the research problem, topical and analytic themes, and desired research products. We found that focal themes generally aided integration potential and became clearer through field visits, discussions with academic and community stakeholders, and team brainstorming. In our IGERT project, the overarching research program helped the teams to identify their focal themes, find integrated team funding opportunities, and develop a common team vision. 


\section{Emphasize problem definition and team proposal writing}

Interdisciplinary proposal writing requires intensive time and effort. Interdisciplinary graduate research programs should be designed to provide enough time to coordinate thorough and detailed proposals, with specific attention to the integrating elements. Integration strategies must build from a base of collaboration, mutual learning, and understanding of epistemological boundaries (Eigenbrode et al. 2007). Research objectives must evolve through all participating team members. Developing the integrated proposal helps to foster common vision and dedication to the project, exposes members to the team's problem-solving approach, highlights the epistemological traditions, and develops the integrated theme. Conceptual mapping (Heemskerk 2003) is a very useful tool when beginning this process. Additionally, we recommend, especially for natural resource and environmental problems, that team members spend time with stakeholders in the field prior to proposal writing to increase their sensitivity to the contexts and boundaries across which they may work.

\section{Target interdisciplinary training}

Interdisciplinary training and/or cross-disciplinary coursework can help mitigate differences in research methods, disciplinary jargon, and paradigms among team members. In our project, participants identified exposure to fields that cross disciplinary boundaries such as landscape ecology, ecological economics, and conservation biology as valuable in this regard. Seminars that cover interdisciplinary topics and tools provide students with additional capacity to understand and use other disciplinary models, frameworks, and paradigms. Training in interdisciplinarity can help all team members to overcome disciplinary constraints, foster creativity, and generate commitment to interdisciplinary work.

\section{Identify mentors to focus on team integration issues}

In addition to individual mentorship, team mentorship is an effective tool for facilitating integrated team research. A team mentor can provide oversight on the progress of the team as a whole and can query the progress of individual team members toward the team research goals. The mentor also can provide an accountability structure for the team. Furthermore, the mentor can help define team objectives, take an active role in guiding teams through conflicts, and help resolve technical problems (Young 2000). Although effective mentorship of graduate student teams is critical, some faculty also found that the mentorship provided by other faculty with more experience in interdisciplinary settings was beneficial. We believe that mentors are valuable throughout one's career and not limited to the academic setting.

\section{CONCLUSIONS}

In conclusion, we offer three main points from our experience in the Integrative Graduate Education and Research Traineeship program delivered jointly by the University of Idaho and Costa Rica's Tropical Agricultural Research and Higher Education Center. First, the demands of disciplinary knowledge within interdisciplinary research remain substantial, and it is incumbent on the participants to link their specializations to the team project. The focus on systemic interactions or interdisciplinary breadth must be considered just as important as the focus on fundamental mechanisms or disciplinary depth in interdisciplinary research. This is especially challenging in the graduate-student research setting.

Second, we conclude that the different degrees of integration, from disciplinary to transdisciplinary, offer different advantages and drawbacks for research. It is important for teams, as well as research programs, to identify the type(s) of integration they will pursue, and understand the challenges to the research process inherent in each. Many teams and programs cannot attempt interdisciplinary or transdisciplinary integration, nor should they (Somerville and Rapport 2000). Problem definition and pragmatism will help to define which degree of integration fits best.

Third, interdisciplinary research can be enabled or challenged by individual personalities, disciplinary distinctions, and programmatic design. Proactive planning and continued reflection on the process of integration throughout the project will help navigate through many potential barriers and identify other prospective bridges. To further the knowledge base on the process of integration, we suggest that others involved in interdisciplinary research, in both the 
academic setting and other interdisciplinary team research environments, document their activities and share their experiences.

Responses to this article can be read online at:

http://www.ecologyandsociety.org/vol12/iss2/art8/responses/

\section{Acknowledgments:}

We extend our gratitude to the faculty and students from the University of Idaho (UI) and the Tropical Agricultural Research and Higher Education Center (CATIE) who participated in the program's annual meeting workshop on integration and provided their valuable insights and experiences essential for this reflection. Specifically, we thank the UI-CATIE Integrative Graduate Education and Research Traineeship (IGERT) Steering Committee: Jan Boll, Nilsa Bosque-Pérez, Steve Brunsfeld, Sanford Eigenbrode, Bryan Finegan, Celia Harvey, Paul McDaniel, Dietmar Stoian, and Lisette Waits. We are especially indebted to the UI-CATIE IGERT studentfellows: Ruth Dahlquist, Shannon Donovan, Caren Goldberg, Thor Hanson, Chris Looney, Chris Lorion, Amy Pocewicz, Beth Polidoro, Mariangie Ramos, Dina Roberts, Yaniria Sánchez de León, Jessica Schedlbauer, Jan Schipper, Steve Sesnie, Ryan Toohey, and Leigh Winowiecki. Finally, we would like to thank the program's external advisory panel members who freely offered their insights and feedback: Pedro Barbosa, Winifred Kessler, and Barry Noon. This work was supported in part by NSF-IGERT grant No. 0114304. Conclusions and recommendations are the responsibility of the authors as are any omissions, errors, or inconsistencies.

\section{LITERATURE CITED}

Benda, L. E., N. L. Poff, C. Tague, M. A. Palmer, J. Pizzuto, S. Cooper, E. Stanley, and G. Moglen. 2002. How to avoid train wrecks when using science in environmental problem solving. Bioscience 52:1127-1136.

Bosque-Pérez, N., L. Waits, P. McDaniel, S. Eigenbrode, J. E. Force, and S. Brunsfeld. 2001. IGERT: ecosystem management in temperate and tropical regions: integrating education in sustainable production and biodiversity conservation. National Science Foundation, Arlington, Virginia, USA.

Brewer, G. D. 1999. The challenges of interdisciplinarity. Policy Sciences 32:327-337.

Bruce, A., C. Lyall, J. Tait, and R. Williams. 2004. Interdisciplinary integration in Europe: the case of the fifth framework programme. Futures 36: $457-470$.

Clark, R. N., G. H. Stankey, P. J. Brown, J. A. Burchfield, R. W. Haynes, and S. F. McCool. 1999. Toward an ecological approach: integrating social, economic, cultural, biological, and physical considerations. Pages 297-318 in N. C. Johnson, A. J. Malk, W. T. Sexton, and R. Szaro, editors. Ecological stewardship: a common reference for ecosystem management. Elsevier Science, Oxford, UK.

Creswell, J. W. 2003. Research design: qualitative, quantitative, and mixed methods approaches. Sage, Thousand Oaks, California, USA.

Eigenbrode, S. D., M. O'Rourke, J. D. Wulfhorst, D. M. Althoff, C. S. Goldberg, K. Merrill, W. Morse, M. Nielsen-Pincus, J. Stephens, L. Winowiecki, and N. A. Bosque-Pérez. 2007. Employing philosophical dialogue in collaborative science. BioScience 57(1):55-64.

Ewel, K. C. 2001. Natural resource management: the need for interdisciplinary collaboration. Ecosystems 4:716-722.

Golde, C. M., and H. A. Gallagher. 1999. The challenges of conducting interdisciplinary research in traditional doctoral programs. Ecosystems 2:281-285.

Graybill, J. K., S. Dooling, V. Shandas, J. Withey, A. Greve, and G. Simon. 2006. A rough guide to interdisicplinarity: graduate student perspectives. BioScience 56(9):757-763.

Gunderson, L. H., and C. S. Holling. 2002. Panarchy: understanding transformations in human and natural systems. Island Press, Washington, D. C., USA.

Heemskerk, M., K. Wilson, and M. PavaoZukerman. 2003. Conceptual models as tools for 
communication across disciplines. Conservation Ecology 7(3):8. [online] URL: www.consecol.org/V ol7/iss3/art8.

Jakobsen, C. H., T. Hels, and W. J. McLaughlin. 2004. Barriers and facilitators to integration among scientists in transdisciplinary landscape analysis: a cross-country comparison. Forest Policy and Economics 6:15-31.

Janssen, W., and P. Goldsworthy. 1996. Multidisciplinary research for natural resource management: conceptual and practical implications. Agricultural Systems 51:259-279.

Jantsch, E. 1970. Inter- and transdisciplinary university: a systems approach to education and innovation. Policy Sciences 1:403-428.

Klein, J. T. 1996. Crossing boundaries: knowledge, disciplinarities, and interdisciplinarities. University Press of Virginia, Charlottesville, Virginia, USA.

Klein, J. T. 2004. Interdisciplinarity and complexity: an evolving relationship. E:CO 6 $(1 / 2): 2-10$.

Lele, S., and R. B. Norgaard. 2005. Practicing interdisciplinarity. Bioscience 55:967-975.

Naiman, R. J. 1999. A perspective on interdisciplinary science. Ecosystems 2:292-295.

National Academy of Sciences, National Academy of Engineering, and Institute of Medicine. 2005. Facilitating interdisciplinary research. National Academy Press, Washington, D. C., USA.

National Science Foundation. 2006. Integrative graduate education research traineeship. [online] URL: www.nsf.gov/funding/pgm summ.jsp? pims $\mathrm{id}=12759$.

Pickett, S. T. A., W. R. J. Burch, and J. M. Grove. 1999. Interdisciplinary research: maintaining the constructive impulse in a culture of criticism. Ecosystems 2:302-307.

Rhoten, D., and A. Parker. 2004. Risks and rewards of an interdisciplinary research path. Science 306(5704):2046.

Rosa, E. A., and G. E. Machlis. 2002. It's a bad thing to make one thing into two: disciplinary distinctions as trained incapacities. Society and Natural Resources 15:251-261.

Rosenfield, P. L. 1992. The potential of transdisciplinary research for sustaining and extending linkages between the health and social sciences. Social Science Medicine 35:1343-1357.

Somerville, M. A., and D. J. Rapport, editors. 2000. Transdisciplinarity: recreating integrated knowledge. EOLSS Publishers, Oxford, UK.

Sillitoe, P. 2004. Interdisciplinary experiences: working with indigenous knowledge in development. Interdisciplinary Science Reviews 29(1):6-23.

Stokols, D., J. Fuqua, J. Gress, R. Harvey, K. Phillips, L. Baesconde-Garbanati, J. Unger, P. Palmer, M. A. Clark, S. M. Colby, G. Morgan, and W. Trochim. 2003. Evaluating transdisciplinary science. Nicotine \& Tobacco Research 5:S21-S39.

University of Idaho and Tropical Agricultural Research and Higher Education Center (CATIE). 2006. Doctoral program in biodiversity conservation and sustainable production in tropical and temperate fragmented landscapes. [online] URL: www.ag.uidaho.edu/igert/.

Young, K. 2000. What makes transdisciplinarity succeed or fail? Second report. Pages 218-220 in M. A. Somerville and D. J. Rapport, editors. Transdisciplinarity: recreating integrated knowledge. EOLSS Publishers, Oxford, UK.

Younglove-Webb, J., B. Gray, C. W. Abdalla, and A. P. Thurow. 1999. The dynamics of multidisciplinary research teams in academia. Review of Higher Education 22:425-440.

Zarin, D. J., K. A. Kainer, F. E. Putz, M.Schmink, and S. K. Jacobson. 2003. Integrated graduate education and research in neotropical working forests. Journal of Forestry 101:31-33. 